\title{
Watershed Infarct due to Massive Pulmonary Embolism: A Rare Diagnosis at the Emergency Department
}

\author{
Gülşah Çıkrıkçı Işık, Şeref Kerem Çorbacıoğlu, Yunsur Çevik \\ Department of Emergency Medicine, Keçiören Training and Research Hospital, Ankara, Turkey
}

\begin{abstract}
Introduction: Watershed infarcts, which involve the hemodynamic risk zones that are the junction of distal fields of nonanastomosing arterial systems, can occur due to hemodynamic mechanisms such as hypotension and hypovolemia.

Case Report: We present the case of an 86-year-old woman who complained of syncope, was confused, had a seizure at the emergency service and was diagnosed with watershed infarct of the right hemisphere, which was secondary to massive pulmonary embolism.

Conclusion: Watershed infarcts can occur due to embolic or hemodynamic mechanisms. Massive pulmonary emboli can cause watershed infarcts via hemodynamic mechanism by causing resistant hypotension. Watershed infarcts coexist with pulmonary embolism; therefore, embolic patients may present with neurological symptoms. Therefore, watershed infarcts must be considered for patients with high risk factors for embolism.
\end{abstract}

Keywords: Pulmonary embolism, watershed infarction, stroke

Received: 23.07.2015 Accepted: 19.11.2015 Available Online Date: 04.02.2016

\section{Introduction}

Watershed infarct (WI), which accounts for $10 \%$ of all cerebral infarcts, is the infarct of the hemodynamic risk zones that are the junction of distal fields of non-anastomosing arterial systems. Reasons of the infarct are embolic or hemodynamic mechanisms (1).

Acute pulmonary embolisms may result in circulatory failure in 10\% of patients via a massive obstruction of the pulmonary arterial bed (2). We report a case diagnosed with WI due to resistant hypotension related to massive pulmonary embolism. We believe that our study has reported an example case of WI caused by hemodynamic mechanism.

\section{Case Report}

We present a case of an 86-year-old woman who was presented to the emergency department due to syncope. Patient's anamnesis revealed that she had chest pain and dyspnea before syncope. Past medical history revealed that she had Parkinson's disease and atrial fibrillation and was under medication.

On initial evaluation, she was confused and seemed pale and toxic. Her vital signs were as follows: blood pressure, 68/52 mmHg; respiratory rate, $18 / \mathrm{min}$; pulse rate, $84 / \mathrm{bpm}$; $\mathrm{sO} 2,88 \%$; temperature, $37^{\circ} \mathrm{C}$. Venous blood gas analyses revealed the following: $\mathrm{pH}$, 7.13; pCO2, $70.6 \mathrm{mmHg}$; pO2, $21 \mathrm{mmHg}$; lactate, $8.7 \mathrm{mmol} / \mathrm{L}$; and glucose, $283 \mathrm{mg} / \mathrm{dL}$. Other laboratory results were normal. Her Glasgow coma score was 14. 
Nonspecific ST-T wave abnormalities were demonstrated on patient's electrocardiography. Bedside echocardiography revealed only right ventricle enlargement and no hypokinetic or akinetic wall segment.

Computerized tomography (CT) of the head demonstrated no acute pathological finding. On follow-up, her confusion progressed. At the 40th min of admission, she had a generalized tonic-clonic seizure and was treated with intravenous diazepam. On control physical examination after seizure, left hemiplegia was detected; therefore, we performed brain diffusion-weighted magnetic resonance imaging. It demonstrated hyperintense lesions extending within the cortical watershed area of middle cerebral artery (MCA) region of the right hemisphere, which is considered as a WI due to severe hypotension. (Figure 1)

In addition, the presence of increased D dimer levels, eco findings, hypoxia, chest pain, and resistant hypotension are considered as symptoms of a possible acute pulmonary embolism. To clarify the

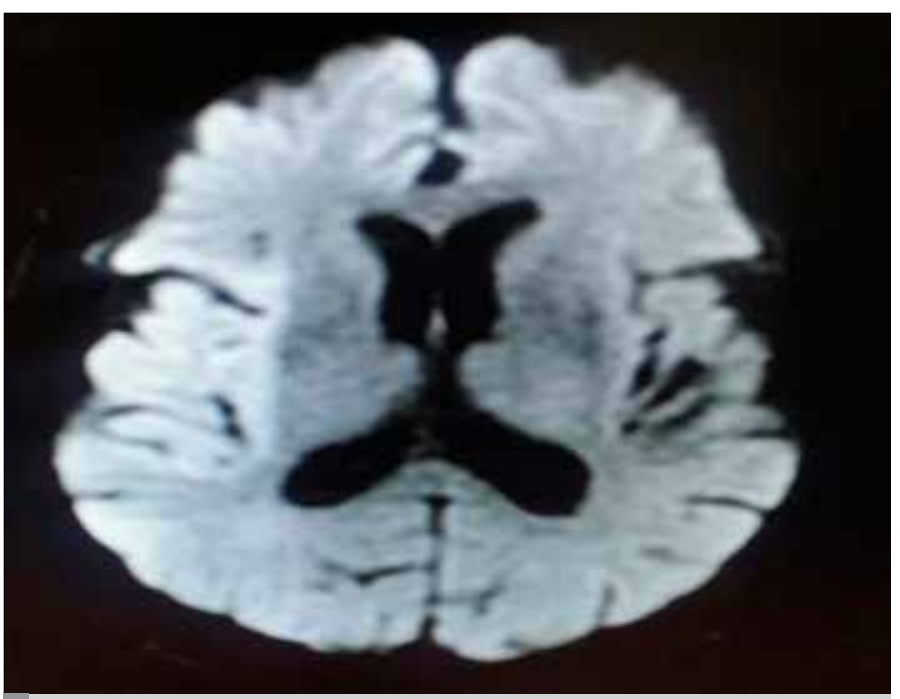

FIG. 1. Brain diffusion-weighted magnetic resonance imagination was demonstrated that hyperintense lesions extending within the cortical watershed area of middle cerebral artery (MCA) region of the right hemisphere.

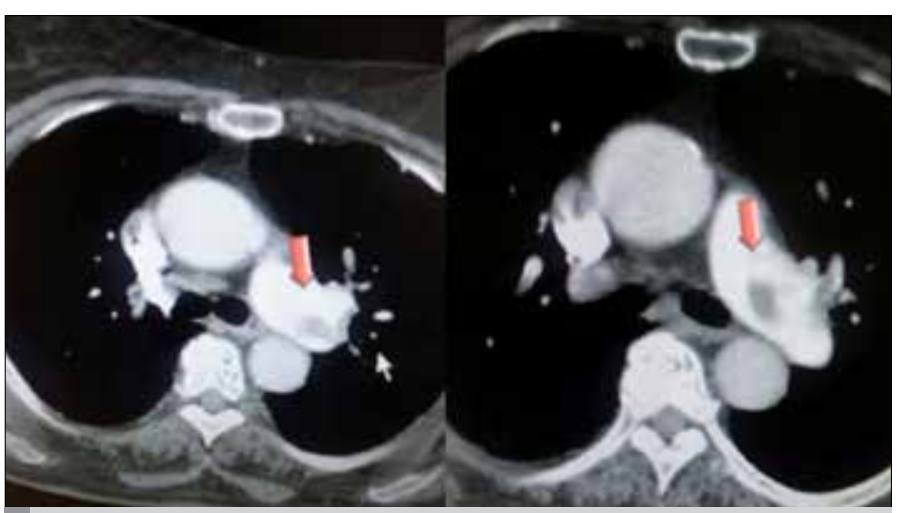

FIG. 2. Bilateral massive pulmonary thromboembolism was shown in thorax CT of the patient. diagnosis, thorax CT enhanced contrast was planned. It demonstrated bilateral massive pulmonary thromboembolism, which was accepted as the reason of the watershed infarction on the MCA region. (Figure 2) Despite thrombolytic treatment indication for pulmonary embolism, we could not perform it because the large infarct region had a high risk of hemorrhage. At the 20th min after PE diagnosis, her vital signs deteriorated and cardiovascular arrest developed. Despite resuscitative procedures, spontaneous circulation did not return and she died.

\section{Discussion}

Watershed infarcts occur at the junction of two artery territories; its pathogenesis is not completely understood, but there are two possible mechanisms have been suggested (1). First, an embolic mechanism in which emboli clearance at watershed areas is decreased. This mechanism seems mostly in patients with malignancy due to hyper coagulation states (3). Second, a hemodynamic mechanism, which is more common. These strokes may often be preceded by specifically precipitating circumstances that induce hypotension and/or hypovolemia, which may be caused by standing up suddenly, exercise, Valsalva's maneuver, administration of antihypertensive drugs, bleeding, and anemia (4). In our patient, hypotension due to massive pulmonary embolism caused by the hemodynamic mechanism clarifies the etiology of watershed infarction.

Symptoms of watershed infarctions may vary according to the affected region. Anterior WI is associated with a contralateral motor deficit, posterior WI is associated with aphasia and hemi hypoesthesia, capsule-thalamic WI mimic the lacunar syndrome due to smallvessel disease, cerebellar WI is associated with vertigo and ataxia, and brainstem WI is associated with coma (4). However, in most of the cases the clinical picture of watershed infarctions is progressive or fluctuating. Symptoms may be mild and are, therefore, probably underestimated (1). Our patient's neurological examination was also normal at the beginning.

Syncope, which might support the hemodynamic hypothesis, is occasionally reported at the onset of cerebral WI (1). Our patient's also complaint of syncope at ED admission. Another characteristic feature of cerebral WI is the early-onset partial seizures, which was also observed in our patient (5).

Acute fatal pulmonary embolism is the most often missed diagnosis in cases of sudden death within the hospital (6). Common risk factors of PE are old age and immobility, and common comorbidities with PE are hypertension, diabetes mellitus, obesity, atrial fibrillation, and hyperlipidemia (6). Echocardiogram demonstrates acute right ventricular overload findings at pulmonary embolism (6). Common symptoms of PE are dyspnea and chest pain, but it can also present with neurological symptoms like near or full syncope, new-onset seizure, new-onset confusion, or stroke.

There are three reported cases of patients with coexisting pulmonary embolism and stroke, where the common mechanism of coexisting stroke is the migration of emboli from a patent foramen ovale 
(PFO) $(7,8,9)$. The first case is of a young woman with no significant medical history who suffered pulmonary embolism and stroke after a long flight from Peru to Spain. This long travel was considered as a risk factor for deep venous thrombosis and emboli (7). The second case is of a young woman who had been diagnosed with PE and stroke because of PFO after undergoing varicose vein stripping of the leg, which is a risk factor for thromboembolism (8). Similarly, in the third case, a renal cancer patient was diagnosed with PE and stroke, and the authors describe the malignancy as a risk factor for thrombus formation (9). In another case report, a HIV positive patient with PE and stroke was reported, and an increased prothrombotic state in HIV patients was described as the risk factor (10). However, the underlying mechanism is different in our case; it was neither due to the increased thrombus formation risk nor the migration of thrombus from the PFO. In our case, stroke was a result of resistant hypotension, which was due to massive pulmonary embolism.

\section{Conclusion}

Physicians should be aware that especially in old and immobile patients with comorbid diseases who present to emergency department with syncope, pulmonary embolism should be considered at differential diagnosis. Massive embolism may cause cardiac failure and resistant hypotension, resulting in watershed infarctions due to hemodynamic mechanisms.

Informed Consent: Written informed consent was obtained from patient who participated in this case.

Peer-review: Externally peer-reviewed.

Author Contributions: Concept - G.Ç.l.; Design - Ş.K.Ç.; Supervision - Ş.K.Ç.; Materials - G.C..I.; Data Collection and/or Processing - G.Ç.I.; Analysis and/or Interpretation - Y.Ç; Literature Review - Y.Ç;Writer - G.Ç.I.; Critical Review - Y.Ç.
Conflict of Interest: The authors declared no conflict of interest.

Financial Disclosure: The authors declared that this study has received no financial support.

\section{References}

1. Juergenson I, Mazzucco S, Tinazzi M. A typical example of cerebral watershed infarct. Clin Pract 2011; 1: e114. [CrossRef]

2. Ozier Y, Dubourg O, Farcot JC, Bazin M, Jardin F, Marqairaz A. Circulatory failure in acute pulmonary embolism. Intensive Care Med 1984; 10: 917. [CrossRef]

3. Lee SP, Hong CT. Widespread watershed infarct in patient with malignancy-related hypercoagulation. Acta Neurol Taiwan 2012; 21: 49-50.

4. D'Amore C, Paciaroni M. Border-zone and watershed infarctions. Front Neurol Neurosci 2012; 30: 181-4. [CrossRef]

5. Denier C, Masnou P, Mapoure Y, Souillard-Scemama R, Guedj T, Theau$\operatorname{din} \mathrm{M}$, et al. Watershed infarctions are more prone than other cortical infarcts to cause early-onset seizures. Arch Neurol 2010; 67: 1219-23. [CrossRef]

6. Okubo S, Yoshioka T, Nakanishi N, Kuineda T, Yutani C, Shimouchhi A. Acute fatal pulmonary embolism: its prevention, diagnosis and treatment. Kokyu To Junkan 1990; 38: 375-81.

7. Belvís R, Masjuan J, Garcia-Barragan N, Cocho D, Marti-Fabreqas J, Santamaria A, et al. Stroke and pulmonary thromboembolism after a long flight. Eur J Neurol 2005; 12: 732-4. [CrossRef]

8. Pelletier M, Buqeaud M, Ibrahim R, Morency G, Kouz S. Successful thrombolysis of a stroke with a pulmonary embolism in a young woman. J Emerg Med 2010; 39: 443-8. [CrossRef]

9. Tournoux F, Loqeart D, Cohen-Solal A. Massive pulmonary embolism and stroke due to thrombus across the foramen ovale. Ann Cardiol Anqeiol 2006; 55: 55-7. [CrossRef]

10. Naidoo P, Hift R. Massive pulmonary thromboembolism and stroke. Case Rep Med 2011; 2011: 398571. [CrossRef] 